Check for updates

Cite this: RSC Adv., 2018, 8, 33129

Received 1st July 2018

Accepted 18th September 2018

DOI: 10.1039/c8ra05611k

rsc.li/rsc-advances

\section{Precipitated silica agglomerates reinforced with cellulose nanofibrils as adsorbents for heavy metals $\uparrow$}

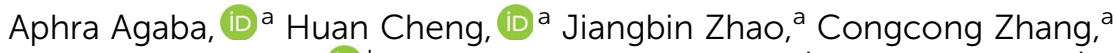 \\ Mike Tebyetekerwa, (iD ${ }^{\mathrm{b}}$ Liduo Rong, ${ }^{a}$ Xiaofeng Sui ${ }^{\star a}$ and Bijia Wang ${ }^{\star a}$
}

Silicon-containing compounds such as silica are effective heavy metal sorbents which can be employed in many applications. This is attributed to the porous nature of hydrothermally-stable silica, endowing such materials with high surface area and rich surface chemistry, all responsible for improving adsorption and desorption performance. However, to this day, the wide application of silica is limited by its skeletal brittleness and high production cost coupled with a risky traditional supercritical drying method. To solve the named problems, herein, precipitated silica agglomerates (referred to as PSA) was crosslinked with TEMPO-oxidized cellulose nanofibrils (TO-CNF) as a reinforcement in the presence of 3aminopropyltriethoxysilane (APTES), via a facile dual metal synthesis approach, is reported. The resultant new silica-based sponges (TO-CNF PSA) showed desirable properties of flexibility, porosity and multifaceted sorption of various heavy metals with re-usability. The experimental results showed maximum adsorption capacities of 157.7, 33.22, 140.3 and $130.5 \mathrm{mg} \mathrm{g}^{-1}$ for $\mathrm{Pb}(॥), \mathrm{Hg}\left({ }^{\prime}\right), \mathrm{Cr}\left({ }^{\prime \prime \prime}\right)$ and $\mathrm{Cd}(॥)$ ions, respectively. Such a facile approach to modify silica materials by attaching active groups together with reinforcement can provide improved and reliable silica-based materials which can be applied in water treatment, gas purification, thermal insulation etc.

\section{Introduction}

Silica has attracted and continues to gather global attention because of its fascinating properties and unique attributes including low dielectric constant (1.1-2.2), low index of refraction ( 1.05) and ease of surface modification. ${ }^{1,2}$ These properties are required in numerous applications such as thermal insulation, cosmic dust collectors, oral detoxication, catalysis, separation of oils and organic liquids, sensors, heavy metal aqueous waste remediation, oil spill clean-up and many others. ${ }^{3-6}$ Amongst these, heavy metal removal by silica and silica-based adsorbents has been extensively investigated. ${ }^{7}$ However, their poor mechanical properties dictated by their skeletal brittleness are some of the underlying problems which limit their wide application. ${ }^{1,8}$

The silica skeletal brittleness can be solved by employing reinforcements in the form of polymers via chemical surface

${ }^{a}$ Key Lab of Science and Technology of Eco-textile, Ministry of Education, College of Chemistry, Chemical Engineering and Biotechnology, Donghua University, Shanghai 201620, People's Republic of China. E-mail: bwang@dhu.edu.cn; suixf@dhu.edu.cn ${ }^{b}$ Research School of Engineering, College of Engineering and Computer Science, The Australian National University, Canberra, Australian Capital Territory, 2601, Australia

$\dagger$ Electronic supplementary information (ESI) available. See DOI: 10.1039/c8ra05611k crosslinking chemistries, strengthening the silica with multifunctional nanoparticles or treatment with silylating agents ${ }^{9}$ and networking with and/or in 1D fibrous materials. ${ }^{10}$ Successful reinforcement of silica with multifunctional nanoparticles in the recent past was demonstrated by Harb et al. ${ }^{11}$ whereby graphene oxide and carbon nanotubes were employed via hydrolytic condensation of tetraethoxysilane.

Nanofibers reinforcement seems to be better approach due to unique properties of $1 \mathrm{D}$ fibrous morphologies which are able to present unlimited mechanical properties, high surface area and facile modification techniques towards silica-based materials. ${ }^{12,13}$ Several works have reported reinforcing of silica with fiber-shaped nanomaterials (structures) in the form of electrospun polymer composite nanofibers and dispersion of the sol in fibrils or nanofibers suspensions. ${ }^{12,14}$ With the growing concerns about sustainability, considerable efforts have recently been targeted towards developing silica reinforcements derived from renewable resources, for example, nanocelluloses (NCs). ${ }^{15}$ NCs are a family of unique cellulosic materials with lateral dimensions in the nano-size range and can exist in 1D fibrils shapes. In addition, to green advantages such as hydrophilicity, biodegradability, biocompatibility, reproducibility, cellulose is one of the most abundant and inexhaustible natural polymers on earth with abundant $-\mathrm{OH}$ groups. However, the -OH groups of pure cellulose have a limited adsorption capacity towards heavy metal ions. ${ }^{16}$ Improving their adsorption requires 
functionalizing the surface of nanocellulose which can allow the incorporation of different chemical moieties (moieties such as amino, carbonyl, sulfo groups and others) and hence enhance its broad applications for example in binding and adsorption against pollutants such as toxic heavy metals and dyes. ${ }^{17}$ The chemical reactivity is highly dependent on the high donor reactivity of -OH groups. APTES is a silane an organosilane with amine group which can chelate metal ions. In addition, the amount of silica introduced into the cellulose structure can be uniquely determined by the APTES moieties that react to the network. The other advantages include ease to surface modification, low density, high aspect ratio and impressive mechanical properties among others. ${ }^{\mathbf{1 8 - 2 1}}$

Green and facile synthesis of highly adsorbent, flexible and multifunctional silica is an excellent approach towards tackling various world problems. More especially heavy metal removal from the environment which metals are seen as a growing health problem worldwide. ${ }^{22-29}$ Cadmium, mercury, lead are in the World Health Organisation's list of top 10 chemicals of public concern. ${ }^{17}$ The practical techniques to eliminate heavy metals from polluted and waste waters are urgently required due to the toxicity associated with non-biodegradability, bioaccumulation of heavy metal ions..$^{2,29,30}$ In addition, there are severe environmental, economic and social impacts associated with heavy metal pollution. ${ }^{17}$ At higher concentrations, heavy metals have neurological impacts, and many are carcinogenic in nature. Statistics details that heavy metal's toxicity occurs even at as low concentrations as $1.0-10 \mathrm{mg} \mathrm{L}{ }^{-1} \cdot{ }^{29}$ Worse still, some strong heavy metals such as $\mathrm{Cd}, \mathrm{Hg}$ are toxic in lower concentrations of $0.001-0.1 \mathrm{mg} \mathrm{L}{ }^{-1} \cdot{ }^{31}$ In fact, several methods can be used to remove heavy metals such as chemical precipitation, membrane filtration, ion exchange, adsorption and reverse osmosis. ${ }^{\mathbf{2 9}, \mathbf{3 2 - 3 4}}$ Nevertheless, most of these methods are costly or ineffective and can generate secondary contaminations ${ }^{35,36}$ Among them, adsorption is considered the most highly efficient, cost-effective with a promising and economical strategy owing to its simplicity, wide adaptability, availability of different adsorbents, high efficiency without yielding harmful by-products. ${ }^{37-39}$

Interesting works on adsorption were done by $\mathrm{Xu}$ et al. (6,40,41 $^{\mathbf{1}}$ They exhaustively studied heavy metal removal and the metal binding capacity on the adsorbents mainly focussing on the innovative development of adsorbents, biosorption performance, re-use, kinetic and isotherm models for future potential applications. The results showed excellent stability in a wide range of temperature and $\mathrm{pH}$. In view of the preceding statements and the published reports such as on testing selectivity, metal binding capacities of adsorbents offered a reasonable basis for the search for new, inherent, environmentally friendly and potentially achievable metal adsorbents. Learning from Twumasi et $a .^{42}$ on preparation and characterisation of the double metal-silica sorbent for gas filtration, in this work a facile strategy was adopted to obtain precipitated silica agglomerates which were later reinforced with cellulose nanofibrils prior to utilising the resultant material as an effective multi heavy metal remover. A parametric study was proposed to understand the kinetics of adsorption thereby studying the potential of silica cellulose-based material in detection and removal of $\mathrm{Pb}$ (II), $\mathrm{Hg}$ (II), $\mathrm{Cr}$ (III) and $\mathrm{Cd}(\mathrm{II})$ ions from aqueous solution.

A combination of several factors such as porous nature of the adsorbent where metal ions can physically be trapped and the presence of amine functional group were considered in selecting TO-CNF PSA as an adsorbent for heavy metal ions. Briefly, the objectives of this work include: (1) search for readily available, most promising and inexpensive adsorbents from a large pool of adsorbents that would simultaneously detect and remove heavy metal ions from aqueous solution; (2) develop the state-of-the-art material by reinforcement and the introduction of metal ions chelating agents; (3) apply the adsorbents to remove heavy metal ions from aqueous solutions, study the kinetics, isotherms and regeneration and later compare with the relevant literature. TO-CNF PSA was indeed demonstrated to have the ability to remove $\mathrm{Pb}$ (II), $\mathrm{Hg}$ (II), and $\mathrm{Cr}$ (III) and $\mathrm{Cd}$ (II) ions from polluted waters. The results showed a high material's affinity for capturing these heavy metal ions even in coexistence. Moreover, the silica-based adsorbent also demonstrated the removal efficiency of above $95 \%$ of all the metal ions tested and the removal efficiency remained above $90 \%$ after multiple adsorption-desorption cycles.

\section{Experimental}

\section{Materials and chemicals}

Magnesium chloride $\left(\mathrm{MgCl}_{2}\right)$, calcium chloride $\left(\mathrm{CaCl}_{2}\right)$, aqueous ammonia solution $\left(\mathrm{NH}_{3} \cdot \mathrm{H}_{2} \mathrm{O}, 25-28 \%\right), n$-hexane, sodium hydroxide $(\mathrm{NaOH})$, hydrochloric acid ( $\mathrm{HCl}, 35 \%)$ ethanol, mercury nitrate monohydrate $\left(\mathrm{Hg}\left(\mathrm{NO}_{3}\right)_{2} \cdot \mathrm{H}_{2} \mathrm{O}\right)$, chromium(III) nitrate monohydrate $\left(\mathrm{Cr}\left(\mathrm{NO}_{3}\right)_{3} \cdot 9 \mathrm{H}_{2} \mathrm{O}\right)$, cadmium nitrate tetrahydrate $\left(\mathrm{Cd}\left(\mathrm{NO}_{3}\right)_{2} \cdot 4 \mathrm{H}_{2} \mathrm{O}\right)$, lead nitrate $\left(\mathrm{Pb}\left(\mathrm{NO}_{3}\right)_{2}\right)$, were all purchased from Sinopharm Chemical Reagent Co. Ltd (Shanghai, China). Sodium silicate $\left(\mathrm{Na}_{2} \mathrm{O} \cdot \mathrm{SiO}_{2}\right)$ was obtained from Yixing Kexin Chemical Trading Co. Ltd. (China). 3-Aminopropyltriethoxysilane (APTES) was sourced from Aladdin Chemical Reagent Co. Ltd. (2,2,6,6-tetramethylpiperidin-1-yl) oxyl (TEMPO)-CNF was bought from Tianjin Haojia Cellulose Co., Ltd (China). Milli-Q water was used in all the experiments. All solvents and reagents were used as received.

\section{Synthesis of PSA}

PSA was synthesized according to the Norberg et al. ${ }^{\mathbf{4 3}}$ and the equation for the reaction is illustrated as eqn (1). In particular, water glass $(10 \mathrm{~mL})$ having a molar ratio of $\mathrm{Na}_{2}: \mathrm{SiO}_{3}(1: 3.3)$ was added to $50 \mathrm{~mL}$ of water and stirred vigorously at $35^{\circ} \mathrm{C}$ for $90 \mathrm{~min}$. Then $3 \mathrm{~mL}$ of $\mathrm{NH}_{3} \cdot \mathrm{H}_{2} \mathrm{O}$ was added dropwise to the mixture solution. $10 \mathrm{~mL}\left(1.5 \mathrm{M} \mathrm{MgCl}\right.$ and $\left.\mathrm{CaCl}_{2}\right)$ was added under heavy stirring, and the solution immediately began to coagulate. The reaction was continued at $35^{\circ} \mathrm{C}$ for $4 \mathrm{~h}$. In order to obtain high porous PSA structure, elimination of capillary stress is critical during drying. ${ }^{\mathbf{4}}$ The precipitate was centrifuged and dispersed in $50 \mathrm{~mL} n$-hexane for 2 days. Finally, the wet gel was dried in the oven under ambient pressure for $2 \mathrm{~h}$ at $105^{\circ} \mathrm{C}$. 
The native PSA derived from sodium silicate was crushed into powder under the small stress of about $30 \mathrm{kPa}$ (Scheme 1A).

$$
\begin{aligned}
\mathrm{Na}_{2} \mathrm{O} \cdot n \mathrm{SiO}_{2}(\mathrm{l}) & +\frac{1}{2} \mathrm{MgCl}_{2}(\mathrm{l})+\frac{1}{2} \mathrm{CaCl}_{2}(\mathrm{l}) \\
& \rightarrow\left(\frac{1}{2} \mathrm{Mg}, \frac{1}{2} \mathrm{Ca}\right) \mathrm{O} \cdot n \mathrm{SiO}_{2}(\mathrm{~s})+2 \mathrm{NaCl}
\end{aligned}
$$

\section{Preparation of TO-CNF PSA}

The preparation started with the covalent coupling of APTES molecules onto TO-CNF network. $10 \mathrm{~g}$ TO-CNF was magnetically stirred in the presence of 3-aminopropyltrimethoxysilane for $3 \mathrm{~h}$. The resulting cross-linked homogeneous mixture was then mixed with the already ultra-sonicated $0.2 \mathrm{~g}$ PSA under continuous stirring for more $3 \mathrm{~h}$. The obtained mixture, named TOCNF PSA was freeze-dried for $24 \mathrm{~h}$ to obtain the desired silica-cellulose nanofibrils adsorbent. The product was predried at $60{ }^{\circ} \mathrm{C}$ for $50 \mathrm{~min}$ to promote further crosslinking prior to use (Scheme 1B).

\section{Metal adsorption studies}

The adsorption of the selected metal ions was studied using a series of various concentrations $\left(50-300 \mathrm{mg} \mathrm{L}^{-1}\right)$ of the stock solution prepared by dissolving a calculated amount of metal salt in Milli-Q water in a volumetric flask (Scheme 1C). The initial $\mathrm{pH}$ of the solution was maintained between 5.5 and 6.5 by using a few drops of $0.1 \mathrm{M} \mathrm{NaOH}$ and $0.1 \mathrm{M} \mathrm{HCl}$ solutions, as this $\mathrm{pH}$ was found desirable for the adsorption. Single metal adsorption was performed in a well-covered $150 \mathrm{~mL}$ beaker. $0.3 \mathrm{~g}$ TO-CNF PSA modified sponge-like material was immersed in $100 \mathrm{~mL}$ (50 ppm) metal ion solution with magnetic stirring at $160 \mathrm{rpm}$ to ensure excellent dispersion. At predetermined time intervals (0.1-48 h), the solutions were withdrawn from the beaker and diluted to meet detection limits and linearity of calibration curves. Inductively Coupled Plasma Optical
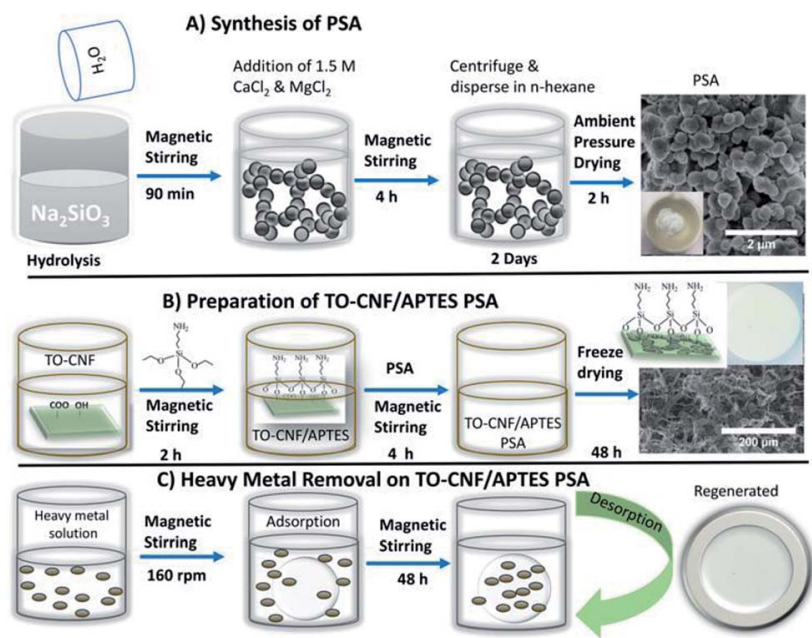

Scheme 1 Summary of synthesis of PSA, preparation of TO-CNF PSA and an illustration of TO-CNF PSA in removing heavy metal ions.
Emission Spectroscopy (ICP-OES) prodigy with a plasma gas flow was used to measure the initial and residual concentrations of the supernatant according to the procedure described by Moss et al. ${ }^{45}$ The pump rate was $100 \mathrm{rpm}$, and the sample

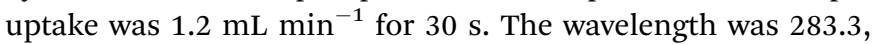
253.7, 267.7 and 214.4 $\mathrm{nm}$ for $\mathrm{Pb}$ (II), $\mathrm{Hg}$ (II), $\mathrm{Cr}$ (III) and $\mathrm{Cd}$ (II) ions, respectively. Initial concentrations were conducted in duplicate, and their average values were used in analyzing the data. The metal uptake capacity, $q$ was computed according to eqn (2).

$$
q=\frac{C_{\mathrm{o}}-C_{t}}{m} V
$$

where $C_{\mathrm{o}}$ and $C_{t}$ are the initial and residual metal ions concentrations ( $\mathrm{mg} \mathrm{L}^{-1}$ ) at time $t$ in solution, $m$ is the mass $(\mathrm{g})$ of adsorbent and $V$ is the volume of adsorbate (L). The amount of metal adsorbed per unit mass of adsorbent $\left(q_{\mathrm{e}}\right)$ is the adsorption at equilibrium $\left(\mathrm{mg} \mathrm{g}^{-1}\right)$ and the percentage of removal efficiency $(R \%)$ were calculated according to eqn (3) and (4), respectively.

$$
\begin{aligned}
q_{\mathrm{e}} & =\frac{C_{\mathrm{o}}-C_{\mathrm{e}}}{m} \times V \\
R \% & =\frac{C_{\mathrm{o}}-C_{\mathrm{e}}}{C_{\mathrm{o}}} \times 100
\end{aligned}
$$

Lagergren pseudo-first order and Lagergren pseudo-second order models were employed to evaluate the removal kinetics. The linearized pseudo-first-order and pseudo-second order kinetic models are expressed according to eqn (5) and (6), respectively. ${ }^{46}$

$$
\begin{gathered}
\log \left(q_{\mathrm{e}}-q_{t}\right)=\log q_{\mathrm{e}}-\frac{k_{1}}{2.303} t \\
\frac{t}{q_{t}}=\frac{1}{k_{2} q_{\mathrm{e}}^{2}}+\frac{t}{q_{\mathrm{e}}}
\end{gathered}
$$

where $q_{\mathrm{e}}$ and $q_{t}$ are the amounts of heavy metals adsorbed (mg $\left.\mathrm{g}^{-1}\right)$ at equilibrium and time $t(\mathrm{~h}) . k_{1}$ and $k_{2}\left(\mathrm{mg} \mathrm{g}^{-1}\right)$ refer to the rate constants for pseudo-first (eqn (4)) and pseudo-second order (eqn (5)) model reactions.

Langmuir and Freundlich isotherm models were used to fit heavy metal removal in this study. Langmuir model assumed that adsorption occurs through a monolayer homogeneous adsorbent surface. The model equation is represented as using eqn (7);

$$
\frac{C_{\mathrm{e}}}{q_{\mathrm{e}}}=\frac{1}{q_{\max } k_{\mathrm{L}}}+\frac{1}{q_{\max }} C_{\mathrm{e}}
$$

where $k_{\mathrm{L}}$ is the Langmuir adsorption constant $\left(\mathrm{mg} \mathrm{L}^{-1}\right), C_{\mathrm{e}}$ is the equilibrium concentration $\left(\mathrm{mg} \mathrm{L}^{-1}\right)$ and $q_{\mathrm{e}}$ is the equilibrium adsorption capacity of adsorbents $\left(\mathrm{mg} \mathrm{g}^{-1}\right) . q_{\max }$ is the maximum monolayer adsorption capacity of adsorbent $(\mathrm{mg}$ $\left.\mathrm{g}^{-1}\right), q_{\mathrm{e}}$ is the equilibrium adsorption capacity of the adsorbent $\left(\mathrm{mg} \mathrm{g}^{-1}\right)$ and can be calculated by plotting $C_{\mathrm{e}} / q_{\mathrm{e}}$ against $C_{\mathrm{e}}$.

The linear form of Freundlich isotherm model is represented in an empirical equation as follows in eqn (8); 


$$
\log q_{\mathrm{e}}=\log K_{\mathrm{F}}-\frac{1}{n} \log C_{\mathrm{e}}
$$

where $K_{\mathrm{F}}$ is the Freundlich constant in relation to adsorption capacity $\left(\mathrm{mg} \mathrm{g}^{-1}\right)$, and $n$ is the Freundlich constant representing adsorption intensity. The values of $K_{\mathrm{F}}$ and $\frac{1}{n}$ can be computed from the slope and intercept by plotting $\log q_{\mathrm{e}}$ against $\log C_{\mathrm{e}}$.

\section{Characterization}

The surface morphologies of the sponges were investigated by Scanning Electron Microscopy (SEM Hitachi TM-3030) at an accelerating voltage of $15 \mathrm{kV}$. All samples were sputter-coated with a thin layer of gold (about $5 \mathrm{~nm}$ ) to ensure excellent conductivity. The functional groups were characterized by Fourier transform infrared spectroscopy (FT-IR); PerkinElmer Spectrum Two, USA in the range of $4000-400 \mathrm{~cm}^{-1}$ at a resolution of $4 \mathrm{~cm}^{-1}$. Chemical bonds were easily identified. X-ray photoelectron spectroscopy (XPS) measurements were performed in (Thermo Fisher ESCALAB 250Xi, USA) instrument using a monochromatic $\mathrm{Al} \mathrm{K} \alpha$ radiation to monitor the elemental compositions. The N 1s, C 1s, O 1s, Si 2p, Hg 4f, Pb 4f, $\mathrm{Cr} 2 \mathrm{p}$ and $\mathrm{Cd} 3 \mathrm{~d}$ peaks were deconvoluted into the components consisting of a Gaussian/Lorentzian line shape function on a linear background (see Fig. S6†). Transmission electron microscopy (TEM) images were prepared by suspending the wet particles of PSA in Milli-Q water and then casting on the carbon coated copper grid. High-resolution TEM images were obtained using (a Joel JEM-2100, Japan). The electron micrographs were recorded on a charge coupled devices (CCD) model US4000 and this camera was attached below the plate-camera of the microscope. The compression tests were conducted on a universal mechanical testing machine (Changchun Xinke universal testing machine, China) with two flat surface compression stages and $1000 \mathrm{~N}$ load cells at room temperature. The compression speed was at $2 \mathrm{~mm} \mathrm{~min}^{-1}$ to investigate the compressive moduli of the samples. Brunauer-Emmett-Teller (BET) method was used to calculate the specific surface areas $\left(S_{\mathrm{BET}}, \mathrm{m}^{2} \mathrm{~g}^{-1}\right)$ from the nitrogen adsorption-desorption isotherms (V-Sorb 2800P, China) in the relative pressure range of $p / p_{0}=0.05-1.0$. The total pore volume $\left(V_{\mathrm{p}}, \mathrm{cm}^{3} \mathrm{~g}^{-1}\right)$ was calculated at $p / p_{0}=0.99$, and Energy-Dispersive X-ray Spectroscopy (EDS) was performed via field emission scanning electron microscopy using Hitachi S-4800 (Japan) to determine the silica content in PSA (see Fig. S3-S5†).

\section{Results and discussion}

\section{Structural morphology and surface properties}

The morphology, size, distribution of PSA, TO-CNF PSA microstructures are shown in Fig. 1. The FE-SEM image of PSA depicts a pearl-neck like structure consisting of spherical silica particles. The PSA contained secondary particles of relatively uniform size (Fig. 1a and b). Representative TEM images of PSA are presented in (Fig. 1c and d) and demonstrate the assembly of particles. A nanoscale porous nature extending from meso $(2-50 \mathrm{~nm}$ ) to macro (above $50 \mathrm{~nm}$ ) was observed in Fig. S1. $\dagger$ This

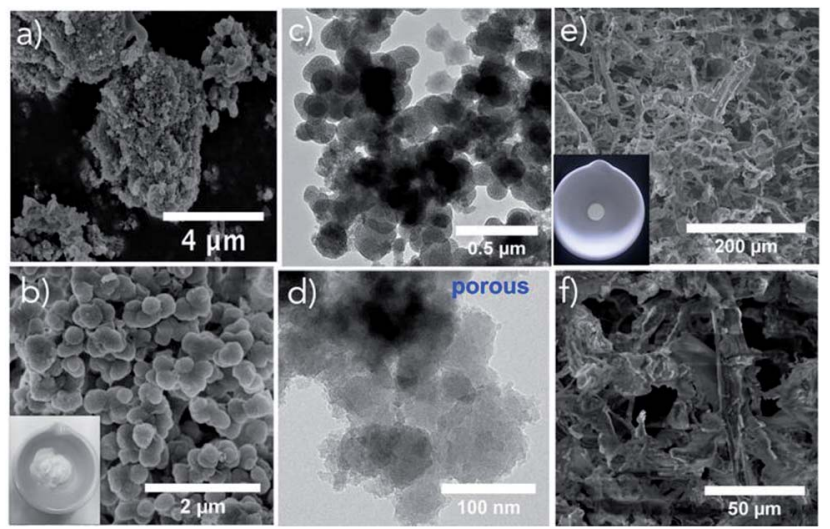

Fig. 1 FE-SEM micrographs of ( $a$ and b) PSA synthesized from precipitation of water glass with calcium and magnesium chloride, (c and d) TEM images showing amorphous and porous nature of PSA, (e and f) SEM images of TO-CNF PSA.

provides critical information, such as the distribution of incorporated particles. The particle sizes are somewhat smaller for the water glass PSA (this work) as compared to that from the alkoxide. ${ }^{47}$ In the presence of TO-CNF, APTES (crosslinker) and PSA, the particles showed some degree of aggregation depending on concentration (Fig. 1e). The particle aggregation in the presence of TO-CNF can be attributed to the formation of a rough coating layer of TO-CNF chains around the particle. ${ }^{48}$ As shown in Fig. 1e and f, PSA is filling the whole macroporosity of TO-CNF matrix. A rough surface is beneficial to metal ion adsorption. ${ }^{49}$ The mesoporous silica structures of TO-CNF PSA are related to those of silica cellulose aerogels reported by other groups with respect to morphology, resembling tentacle patterns of a coral. ${ }^{50}$

The grafting of Si-O-Si groups to PSA, modification with TOCNF (organic moieties in the matrix) was confirmed by means of FT-IR and XPS. FT-IR results of TO-CNF PSA confirm the presence of organic moieties compared to the pristine TO-CNF and PSA. From Fig. 2a, the broad band between 3000 and $3500 \mathrm{~cm}^{-1}$ observed for TO-CNF and TO-CNF PSA are assigned to the stretching mode of $-\mathrm{NH}$ and $-\mathrm{OH}$ adsorption bond respectively. The adsorption peaks near 1053 and $558 \mathrm{~cm}^{-1}$ are attributed to Si-O-Si vibrations. ${ }^{51}$ The broad peak at $1630 \mathrm{~cm}^{-1}$ is ascribed to amide II $\mathrm{C}-\mathrm{N} / \mathrm{N}-\mathrm{H} \mathrm{N}-\mathrm{H}$ vibration in APTES. An additional band for $-\mathrm{CH}_{2}-$ asymmetric stretching mode was observed at $2905 \mathrm{~cm}^{-1}$ which can be linked to the carbon chains of organosilane molecules. These analyses and SEM illuminate that TO-CNF PSA had a porous structure and confirmed its successful surface modification by APTES. A porous structure can physically trap metal ions, and the amino group binds them. ${ }^{52}$

A compressive test was performed in order to study the mechanical property of TO-CNF PSA (Fig. 2b). Mechanically stable adsorbents are essential during heavy metal adsorption process to avoid deformations and shatters. It is clear from the figure that TO-CNF PSA developed high mechanical strength at $80 \%$ strain and withstood a compressive strength of about $12 \mathrm{MPa}$. The sponge is assumed to contain an interpenetrating 

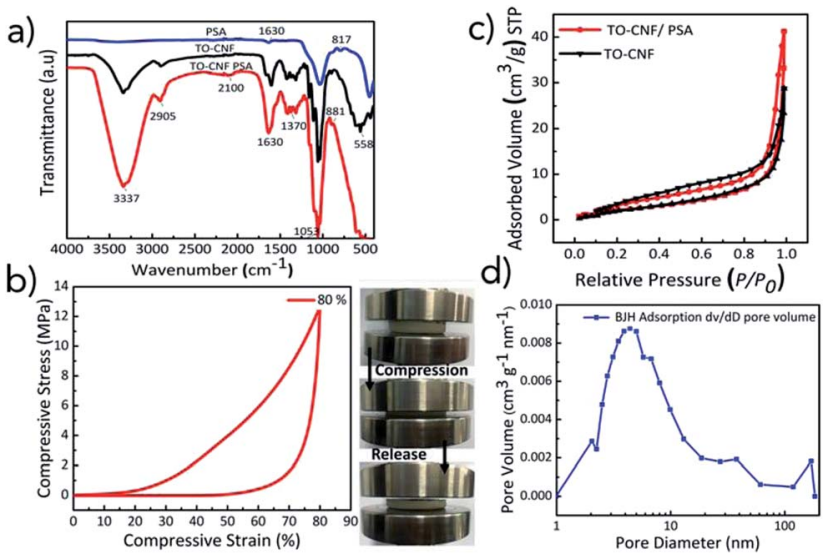

Fig. 2 Characterization and properties of (a) FT-IR spectra, (b) mechanical properties of TO-CNF PSA; compressive stress strain curve at the stress of $80 \%$ and digital images during the compressionrelease process, (c) nitrogen adsorption desorption isotherms of TOCNF PSA and TO-CNF obtained via freeze drying method and (d) poresize distribution plot of TO-CNF PSA calculated from the adsorption isotherm by $\mathrm{BJH}$ technique.

hybrid surface reinforcing the fragile $\mathrm{Si}-\mathrm{O}-\mathrm{Si}$ bonds to build a mechanically strong skeleton. It is suggested that TO-CNF may play a significant part in solving the skeletal brittleness of PSA by enhancing the flexibility and relaxing compression stress. The flexibility and compressibility of TO-CNF PSA promise various potential functionalities such as easy manipulation, convenient storage and good recyclability.

Nitrogen adsorption/desorption isotherms of TO-CNF and TO-CNF PSA sponge were recorded as shown in (Fig. 2c) to investigate the surface and the pore texture of TO-CNF PSA. The porosity and surface changes of PSA were determined by measuring the pore volumes, pore diameters and surface area $S_{\mathrm{BET}}$. The increase in the quantity of gas absorbed implies the existence of microspores. The absence of a plateau at high relative pressures in the isotherms of both PSA (Fig. S2 $\dagger$ ) and TO-CNF PSA sponge (Fig. 2c) suggests some degree of macroporosity (above $50 \mathrm{~nm}$ ). ${ }^{53}$ The hysteresis loops noted for all silica-based materials at $P / P_{0}>0.5$ are typical for spherical shaped pores. The isotherms obtained for all the samples are Type II and IV which is a characteristic feature of the mesoporous materials.

The Specific Surface Area (SSA) of TO-CNF PSA, TO-CNF and PSA was calculated using Brunauer-Emmett-Teller (BET) model. The experimental results on specific surface areas, total pore volume and average pore diameter of the samples have been compiled in (Table S1 $\dagger$ ). These textural properties of PSA are consistent with those reported for Quartzene ${ }^{\circledR}$ prepared by Svenska Aerogel AB using related procedures. ${ }^{43}$ The SSA value of TO-CNF PSA was found to be higher than that of TO-CNF but lower than PSA. The increases in BET surface area of TO-CNF PSA in comparison with plain TO-CNF is anticipated to assist in adsorption of $\mathrm{Pb}$ (II), $\mathrm{Hg}$ (II) $\mathrm{Cr}$ (III) and $\mathrm{Cd}$ (II) ions from aqueous solutions.

The pore size distributions of PSA modified with up to $0.8 \%$ TO-CNF did not reveal dominant mesopores (Fig. 2d). Most of the pores have a size in the range of $4-9 \mathrm{~nm}$. These pore-size distributions explain the observed difference in the optical transparency of the two samples (average pore diameter values in Table S1 $\dagger$ ). It is conceivable that some smaller pore size mesopores were covered by TO-CNF. This could be ascribed to interpenetrating meso and macro structure of PSA. The mesoporosity (pores below $50 \mathrm{~nm}$ ) is the result of surface modification and macroporosity (pores above $50 \mathrm{~nm}$ ) is due to interparticle porosity arising from low silica content.

\section{Adsorption of heavy metal ions by TO-CNF PSA}

The experimental adsorption data was fitted with pseudo-first and pseudo-second order kinetic models and Langmuir and Freundlich isotherms. As shown in Fig. $3 \mathrm{c}$ and d, the kinetic data for the adsorption of $\mathrm{Pb}$ (II), $\mathrm{Hg}$ (II), $\mathrm{Cr}$ (III) and $\mathrm{Cd}(\mathrm{II})$ ions by TO-CNF PSA were fitted to pseudo-first and pseudo-second order models respectively. In general, higher linear correlation coefficients $\left(R^{2}=0.979\right.$ to 0.999$)$ were obtained for pseudosecond order kinetic model indicating that adsorption of $\mathrm{Pb}$ (II), $\mathrm{Hg}$ (II), $\mathrm{Cr}$ (III) and $\mathrm{Cd}(\mathrm{II})$ ions is controlled mainly by chemisorption. ${ }^{54}$ Pseudo second order model proposes a biomolecular interaction between the adsorbate and adsorbent where exchange and sharing of electrons are involved consistent with the presence of chelating amine groups within TO-CNF PSA. More adsorption sites on TO-CNF PSA were occupied as the adsorption time increased and later causing steric hinderance. The adsorption rates slowed down until the equilibrium point was attained. The adsorption ability of TOCNF PSA could be ascribed to the strong metal chelating ability of the amino group and the porous structure (see SEM images). It is assumed that when TO-CNF PSA was immersed in the solution containing heavy metal ions, the metal ions easily diffused into and were chelated by the amino groups of APTES.
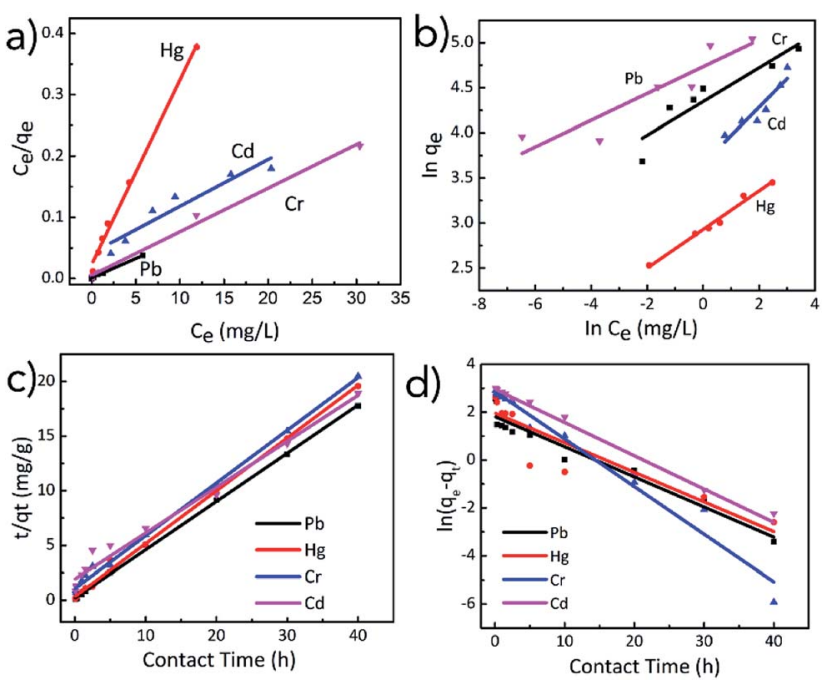

Fig. 3 Linearized ( $a$ and $b$ ) Langmuir and Freundlich isotherm models ( $c$ and d) pseudo-second-order and pseudo-first order kinetic models for removal of $\mathrm{Pb}(॥), \mathrm{Hg}(॥), \mathrm{Cr}\left({ }^{\prime \prime}\right)$ and $\mathrm{Cd}(॥)$ ions on TO-CNF PSA. Note; heavy metals concentration was $50 \mathrm{ppm}$, mass of adsorbent was $0.3 \mathrm{~g}$ and volume of metal ion solution was $100 \mathrm{~mL}$. 
Table 1 Langmuir and Freundlich model fitting parameters for $\mathrm{Pb}(॥), \mathrm{Hg}(॥), \mathrm{Cr}\left({ }^{\prime \prime}\right)$ and $\mathrm{Cd}(॥)$ ions adsorption on TO-CNF PSA

\begin{tabular}{|c|c|c|c|c|c|c|}
\hline Metals & \multicolumn{3}{|c|}{ Langmuir model } & \multicolumn{3}{|l|}{ Freundlich model } \\
\hline $\mathrm{Hg}(\mathrm{II})$ & 33.22 & 1.308 & 0.99337 & 18.69 & 1.015 & 0.98056 \\
\hline $\mathrm{Cr}(\mathrm{III})$ & 140.3 & 0.184 & 0.99256 & 77.26 & 5.346 & 0.83400 \\
\hline $\mathrm{Cd}(\mathrm{II})$ & 130.5 & 1.398 & 0.88958 & 38.75 & 3.185 & 0.84388 \\
\hline
\end{tabular}

It was also observed in Fig. $3 c$ that metal ion adsorption rates by TO-CNF PSA were rapid in the initial stage and then steadily decreased. The fast adsorption process could be ascribed to the readily available adsorbent sites that were instantaneously utilised.

Adsorption isotherms reveal how molecules exposed to adsorption disperse themselves between solid and liquid phases at equilibrium time. Some insights into the adsorption mechanism, affinities of the adsorbent and surface properties are specified. As shown in the fitting plots (Fig. 3a and b), the Langmuir isotherm adsorption model $\left(R^{2}\right.$ values ranging from 0.890 to 0.993 ) is more suitable to describe adsorption process rather than the Freundlich isotherm model. The results indicated that adsorbate-adsorbent interactions were neglectable and the adsorption of metal ions adopted a mono-layer fashion. This is suggested by the finite number of identical sites on the surface facilitating chemical ion exchange processes (Table 1).

\section{Thermodynamic study}

In our analysis, three important thermodynamics parameters as enthalpy of adsorption $\left(\Delta H^{\circ}\right)$, entropy of adsorption $\left(\Delta S^{\circ}\right)$ and the Gibbs free energy of adsorption $\left(\Delta G^{\circ}\right)$ were studied to determine the spontaneous nature of the processes. He et al. ${ }^{36}$ studied the effects of temperature on biosorption of $\mathrm{Cd}(\mathrm{II})$ in the temperature range of 15 to $45^{\circ} \mathrm{C}$. In this work, closely related to that of He and coworkers, the temperature range was adopted and the adsorption experiments were carried out in the temperature range of $25,35,45,55$ and $65^{\circ} \mathrm{C}$. The temperaturedependent adsorption isotherms can be computed using the following equations eqn (9)-(11).

$$
\begin{gathered}
K_{\mathrm{d}}=\frac{\left(C_{\mathrm{o}}-C_{t}\right) V}{C_{t} m} \\
\Delta G^{\circ}=-R T \ln K \\
\Delta G^{\circ}=\Delta H^{\circ}-T \Delta S^{\circ}
\end{gathered}
$$

where $R\left(8.314 \mathrm{~J} \mathrm{~mol}^{-1} \mathrm{~K}^{-1}\right)$ and $T(\mathrm{~K})$ are the universal gas constant and absolute temperature, respectively. $K_{\mathrm{d}}$ is the adsorption coefficient, $C_{\mathrm{o}}$ is the initial concentration of metal ion solution $\left(\mathrm{mg} \mathrm{L}^{-1}\right), C_{\mathrm{e}}\left(\mathrm{mg} \mathrm{L}^{-1}\right)$ is the equilibrium concentration, $V(\mathrm{~mL})$ is the volume of the solution and $m(\mathrm{~g})$ is the mass of adsorbent. The values of $\Delta H^{\circ}$ and $\Delta S^{\circ}$ were determined from the slope and intercept of the plots of $\ln K_{\mathrm{d}}$ versus $\frac{1}{T}$. The $\Delta G^{\circ}$ values were calculated using eqn (11).
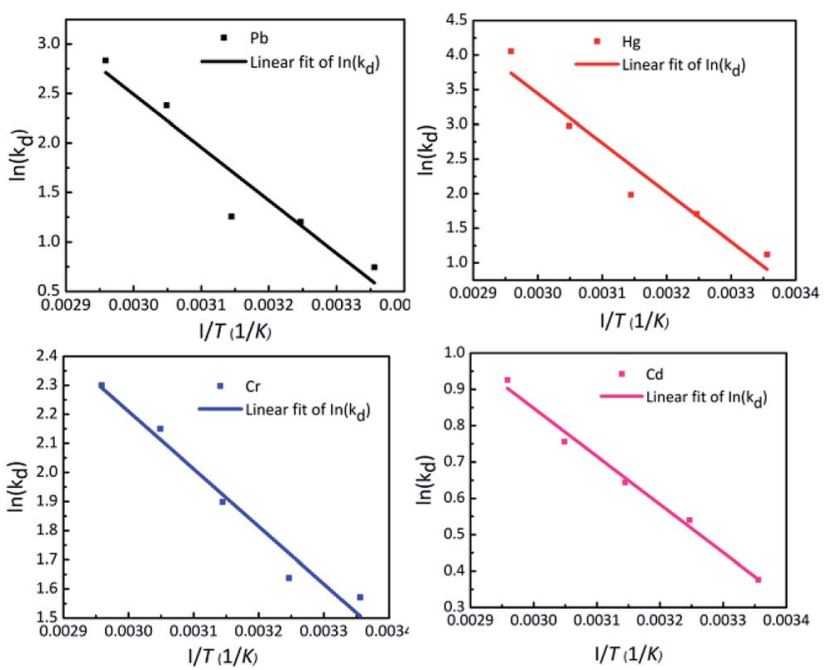

Fig. 4 Plot of $\ln K_{\mathrm{d}}$ versus $1 / T$ for the adsorption of $\mathrm{Pb}(॥), \mathrm{Hg}(॥), \mathrm{Cr}\left({ }^{\prime \prime \prime}\right)$ and $\mathrm{Cd}(\Perp)$ by TO-CNF PSA at different temperatures (concentration is

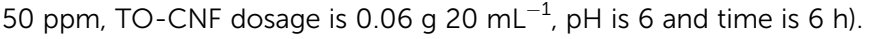

The effect of temperature on adsorption of $\mathrm{Pb}$ (II), $\mathrm{Hg}$ (II), $\mathrm{Cr}$ (III) and Cd(II) by TO-CNF PSA is shown in vant's Hoff plot in Fig. 4. The magnitude of free energy change, $\Delta G^{\circ}$ shifted to a high negative value with elevating temperature from 25 to $65^{\circ} \mathrm{C}$ (Table S3†), signifying that the adsorption process becomes spontaneous, rapid and more favourable at higher temperature. The positive values of enthalpy change $\left(\Delta H^{\circ}=44.5,59.3,16.4\right.$ and $11.0 \mathrm{~kJ} \mathrm{~mol}^{-1}$ ) indicate that metals adsorption on TO-CNF PSA is an endothermic process. The positive values of entropy $\left(\Delta S^{\circ}=\right.$ 154.2, 206.5, 67.7 and $40.1 \mathrm{~J} \mathrm{~mol}^{-1} \mathrm{~K}^{-1}$ ) suggest an increased randomness at the solid-solution interface during adsorption of $\mathrm{Pb}$ (II), $\mathrm{Hg}$ (II), $\mathrm{Cr}(\mathrm{III})$ and $\mathrm{Cd}$ (II) respectively. The calculated values of thermodynamic parameters are presented in Table S3.†

\section{Comparison of $\mathrm{Pb}$ (II), $\mathrm{Hg}$ (II), $\mathrm{Cr}$ (III) and $\mathrm{Cd}$ (II) uptake on TO- CNF PSA with other adsorbents}

The adsorption capacities for each heavy metal ion studied were calculated from the Langmuir equation, as well as measured experimentally and compared to those of previously reported adsorbents in Table 2. It is clear that TO-CNF PSA described in this work records $q_{\max }$ values higher than for other related adsorbents in literature. For example, the adsorption capacity of Cd ions $\left(130.5 \mathrm{mg} \mathrm{g}^{-1}\right)$ is higher than that of cellulose or silica based adsorbents such as silica-ketoenol-furan $\left(55.5 \mathrm{mg} \mathrm{g}^{-1}\right)^{49}$ and many others. 
Table 2 Comparison of sorption capacities of TO-CNF PSA and reported values on various adsorbents for $\mathrm{Pb}(॥), \mathrm{Hg}(॥), \mathrm{Cr}\left({ }^{\prime \prime}\right)$ and $\mathrm{Cd}(॥)$ ions

\begin{tabular}{|c|c|c|c|}
\hline Adsorbent & $\begin{array}{l}q_{\max } \\
\left(\mathrm{mg} \mathrm{g}^{-1}\right)\end{array}$ & $\begin{array}{l}\text { Heavy } \\
\text { metal(s) }\end{array}$ & Ref. \\
\hline TO-CNF PSA & 157.7 & $\mathrm{~Pb}(\mathrm{II})$ & $\begin{array}{l}\text { This } \\
\text { work }\end{array}$ \\
\hline $\begin{array}{l}\text { Surface functionalized } \\
\text { porous lignin (SEPL) }\end{array}$ & 188 & & 55 \\
\hline Cellulose-based hybrid beads & 44 & & 56 \\
\hline Silica aerogel-like materials & 125.1 & & 57 \\
\hline Magnetic cellulose/activated carbon & 37.9 & & 58 \\
\hline $\begin{array}{l}\text { Partially reduced graphene oxide/IT- } \\
\text { PRGO }\end{array}$ & 102.2 & & 59 \\
\hline Silica-ketoenol-furan & 19.07 & & 49 \\
\hline TO-CNF PSA & 140.3 & $\operatorname{Cr}(\mathrm{III})$ & $\begin{array}{l}\text { This } \\
\text { work }\end{array}$ \\
\hline $\begin{array}{l}\text { Chitosan/reduced graphene oxide/ } \\
\text { montmorillonite }\end{array}$ & 87.03 & & 60 \\
\hline Ethyl cellulose/polyethyleneimine & 36.8 & & 54 \\
\hline Cellulose-clay composite biosorbent & 22.2 & & 61 \\
\hline Chitosan activated with organic liquids & 20.8 & & 62 \\
\hline TO-CNF PSA & 33.2 & $\mathrm{Hg}(\mathrm{II})$ & $\begin{array}{l}\text { This } \\
\text { work }\end{array}$ \\
\hline $\begin{array}{l}\text { Poly vinyl alcohol (PVA)-cellulose } \\
\text { nanofibril (CNF) hybrid aerogels }\end{array}$ & 157 & & 63 \\
\hline $\begin{array}{l}\text { Polypyrrole multilayer-laminated } \\
\text { cellulose }\end{array}$ & $\begin{array}{l}25.3- \\
74.9\end{array}$ & & 64 \\
\hline Thol-amine cellulose/amine cellulose & $38 / 7.2$ & & 65 \\
\hline Silica polyacrylamide/hybrid aerogels & $\begin{array}{l}17.6 / \\
13.6\end{array}$ & & 66 \\
\hline TO-CNF PSA & 130.5 & $\mathrm{Cd}(\mathrm{II})$ & $\begin{array}{l}\text { This } \\
\text { work }\end{array}$ \\
\hline Coffee grounds and wheat straws & $\begin{array}{l}31.6 / \\
16.2\end{array}$ & & 67 \\
\hline $\begin{array}{l}\text { Ionic imprinted silica-supported hybrid } \\
\text { sorbent }\end{array}$ & 31.4 & & 68 \\
\hline Silica-ketoenol-furan & 55.5 & & 49 \\
\hline
\end{tabular}

\section{Desorption studies and regeneration of adsorbent}

Efficient regeneration of adsorbent is one of the most critical challenges that need urgent action. Consecutive adsorption/ desorption cycles for $\mathrm{Pb}$ (II), $\mathrm{Hg}$ (II), $\mathrm{Cr}(\mathrm{III})$ and $\mathrm{Cd}(\mathrm{II})$ were conducted via variation of the primary adsorbent. After each adsorption cycle, the adsorbent was treated with $1 \mathrm{M} \mathrm{HCl}$ and $0.1 \mathrm{M} \mathrm{NaOH}$ solutions and milli-Q water consequently for regeneration. As shown in Table $\mathrm{S} 4, \dagger$ the decrease in adsorption
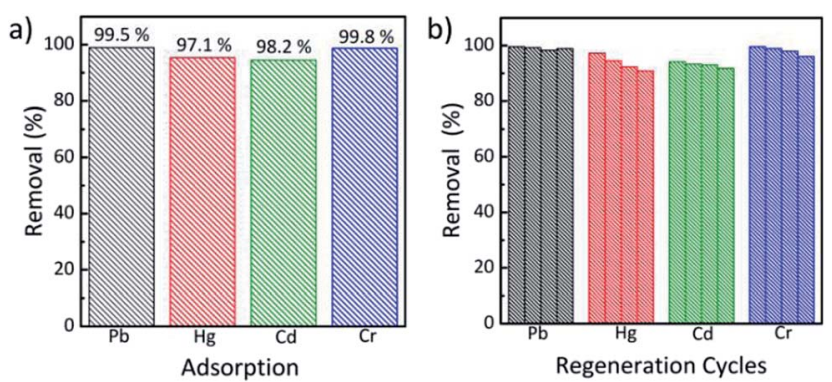

Fig. 5 (a) $\mathrm{Pb}(॥), \mathrm{Hg}(॥), \mathrm{Cr}\left({ }^{\prime \prime}\right)$ and $\mathrm{Cd}(॥)$ removal efficiency and (b) removal efficiency by TO-CNF PSA during 4 regeneration cycles. capacity of the TO-CNF PSA for the metal ions after first regeneration ranged from $5.5 \%$ for $\mathrm{Cr}$ (III) to $24.7 \%$ for $\mathrm{Cd}$ (II), but subsequent regeneration cycles didn't cause further drop in adsorption capacities. This could be due to inadequate removal of strongly adsorbed ions by the acid treatment. Fig. 5 summarises the removal rates for the metal ions in 4 repeat cycles, in which the removal efficiency of above $90 \%$ was attained for all the metal ions studied.

\section{Conclusions}

A cost-effective and eco-friendly silica-cellulose based material, TO-CNF PSA was synthesized from sodium silicate, calcium chloride and magnesium chloride via a facile dual metal synthesis approach. This was followed by reinforcement with TO-CNF in the presence of APTES as a crosslinking agent. The TO-CNF PSA was studied as a heavy metals remover from contaminated water. The material showed excellent performance towards this application. To be specific, fitting with the adsorption kinetics and isotherm, the TO-CNF PSA material's adsorption of $\mathrm{Pb}$ (II), $\mathrm{Hg}$ (II), $\mathrm{Cr}$ (III) and $\mathrm{Cd}$ (II) best fitted pseudosecond order kinetics model and Langmuir isotherm with the maximum adsorption capacity of $157.7 \mathrm{mg} \mathrm{g}^{-1}, 33.2 \mathrm{mg} \mathrm{g}^{-1}$, $140.3 \mathrm{mg} \mathrm{g}^{-1}$ and $130.5 \mathrm{mg} \mathrm{g}^{-1}$ respectively. Moreover, the material could be reused after different adsorption/desorption cycles with its heavy metal ion removal retention ability of at least $\sim 90 \%$.

\section{Conflicts of interest}

There are no conflicts to declare.

\section{Acknowledgements}

This work was financially supported by the Fundamental Research Funds for the Central Universities (No. 2232018A3-04 and No. 2232018-02), the National Key R \& D Program of China (No. 2016YFC0802802) and the Programme of Introducing Talents of Discipline to Universities (No. 105-07-005735).

\section{References}

1 L. Jiang, K. Kato, K. Mayumi, H. Yokoyama and K. Ito, ACS Macro Lett., 2017, 6, 281-286.

2 J. Fricke, J. Non-Cryst. Solids, 1988, 100, 169-173.

3 T. Sangvanich, J. Morry, C. Fox, W. Ngamcherdtrakul, S. Goodyear, D. Castro, G. E. Fryxell, R. S. Addleman, A. O. Summers and W. Yantasee, ACS Appl. Mater. Interfaces, 2014, 6, 5483-5493.

4 J. L. Mohanan, I. U. Arachchige and S. L. Brock, Science, 2005, 307, 397-400.

5 Y. Oh, S. Bag, C. D. Malliakas and M. G. Kanatzidis, Chem. Mater., 2011, 23, 2447-2456.

6 D. W. Lee and B. R. Yoo, J. Ind. Eng. Chem., 2016, 38, 1-12.

7 S. Li, X. Yue, Y. Jing, S. Bai and Z. Dai, Colloids Surf., A, 2011, 380, 229-233. 
8 R. Ciriminna, A. Fidalgo, V. Pandarus, L. M. Ilharco and M. Pagliaro, Chem. Rev., 2013, 113, 6592.

9 S. A. Mahadik, F. Pedraza, V. G. Parale and H. H. Park, J. NonCryst. Solids, 2016, 453, 164-171.

10 T. Pirzada, S. A. Arvidson, C. D. Saquing, S. S. Shah and S. A. Khan, Langmuir, 2014, 30, 15504-15513.

11 S. V. Harb, S. H. Pulcinelli, C. V. Santilli, K. M. Knowles and P. Hammer, ACS Appl. Mater. Interfaces, 2016, 8, 1633916350.

12 O. Nechyporchuk, R. Bordes and T. KãHnke, ACS Appl. Mater. Interfaces, 2017, 9, 39069-39077.

13 N. Mohammed, N. Grishkewich and K. C. Tam, Environ. Sci.: Nano, 2018, 5, 623-658.

14 M. A. B. Meador, S. L. Vivod, L. McCorkle, D. Quade, R. M. Sullivan, L. J. Ghosn, N. Clark and L. A. Capadona, J. Mater. Chem. A, 2008, 18, 1843-1852.

15 B. Duan, H. Gao, M. He and L. Zhang, ACS Appl. Mater. Interfaces, 2014, 6, 19933-19942.

16 H. Ge, H. Huang, M. Xu and Q. Chen, Cellulose, 2016, 23, 2527-2537.

17 D. A. Gopakumar, S. Manna, D. Pasquini, S. Thomas and Y. Grohens, in New Polymer Nanocomposites for Environmental Remediation, eds. C. M. Hussain and A. K. Mishra, Elsevier, 2018, pp. 469-486, DOI: 10.1016/B978-012-811033-1.00019-6.

18 L. Rong, Z. Zhu, B. Wang, Z. Mao, H. Xu, L. Zhang, Y. Zhong and X. Sui, Cellulose, 2018, 25, 3025-3035.

19 X. Zhang, Y. Wang, J. Zhao, M. Xiao, W. Zhang and C. Lu, ACS Sustainable Chem. Eng., 2016, 4, 4321-4327.

20 D. K. Dr, B. H. Dr, H. P. F. Habil and A. B. Dr, Angew. Chem., Int. Ed. Engl., 2005, 117, 3422-3458.

21 H. Cheng, Y. Li, B. Wang, Z. Mao, H. Xu, L. Zhang, Y. Zhong and X. Sui, Cellulose, 2017, 25, 573-582.

22 K. Rehman, F. Fatima, I. Waheed and M. S. H. Akash, J. Cell. Biochem., 2017, 119, 157-184.

23 M. D'Halluin, J. Rullbarrull, G. Bretel, C. Labrugère, E. L. Grognec and F. Felpin, ACS Sustainable Chem. Eng., 2017, 5, 1965-1973.

24 Z. Liu, G. Qian, Y. Sun, R. Xu, J. Zhou and Y. Xu, Energy Fuels, 2010, 24, 2470-2478.

25 M. Podar, C. C. Gilmour, C. C. Brandt, A. Soren, S. D. Brown, B. R. Crable, A. V. Palumbo, A. C. Somenahally and D. A. Elias, Sci. Adv., 2015, 1, e1500675.

26 G. Chen and L. Shi, RSC Adv., 2017, 7, 43445-43454.

27 J. Wang and C. Chen, Biotechnol. Adv., 2009, 27, 195-226.

28 D. M. Guo, Q. D. An, Z. Y. Xiao, S. R. Zhai and Z. Shi, $R S C$ Adv., 2017, 7, 54039-54052.

29 J. Wang and C. Chen, Biotechnol. Adv., 2006, 24, 427-451.

30 Y. Yu, Z. Hu, Z. Chen, J. Yang, H. Gao and Z. Chen, RSC Adv., 2016, 6, 97523-97531.

31 I. Alkorta, J. Hernández-Allica, J. M. Becerril, I. Amezaga, I. Albizu and C. Garbisu, Rev. Environ. Sci. Biotechnol., 2004, 3, 71-90.

32 D. Vilela, J. Parmar, Y. Zeng, Y. Zhao and S. Sánchez, Nano Lett., 2016, 16, 2860-2866.
33 C. J. Madadrang, H. Y. Kim, G. Gao, N. Wang, J. Zhu, H. Feng, M. Gorring, M. L. Kasner and S. Hou, ACS Appl. Mater. Interfaces, 2012, 4, 1186-1193.

34 S. Khosravihaftkhany, N. Morad, A. Z. Abdullah, T. T. Teng and N. Ismail, RSC Adv., 2015, 5, 106498-106508.

35 Y. Huang, C. Yang, Z. Sun, G. Zeng and H. He, RSC Adv., 2015, 5, 11475-11484.

36 H. J. He, Z. H. Xiang, X. J. Chen, H. Chen, H. Huang, M. Wen and C. P. Yang, Int. J. Environ. Sci. Technol., 2017, 15, 1-10.

37 P. K. R. Tay, P. Q. Nguyen and N. S. Joshi, ACS Synth. Biol., 2017, 6, 1841-1850.

38 J. Liu, X. Ge, X. Ye, G. Wang, H. Zhang, H. Zhou, Y. Zhang and H. Zhao, J. Mater. Chem. A, 2016, 4, 1970-1979.

39 C. Kim, S. S. Lee, B. J. Lafferty, D. E. Giammar and J. D. Fortner, Environ. Sci.: Nano, 2018, 5, 556-563.

40 H. Huang, X. Wang, H. Ge and M. Xu, ACS Sustainable Chem. Eng., 2016, 4, 3334-3343.

41 H. Huang, L. Hou, F. Zhu, J. Li and M. Xu, RSC Adv., 2018, 8, 9334-9343.

42 E. Twumasi Afriyie, P. Norberg, C. Sjöström and M. Forslund, Adsorption, 2013, 19, 49-61.

43 S. P. Norberg, J. Abrahamsson and L. G. Lindahl, US Pat. No. $7,736,611$, U.S. Patent and Trademark Office, Washington, DC, 2010.

44 H. Liu, W. Sha, A. T. Cooper and M. Fan, Colloids Surf., A, 2009, 347, 38-44.

45 J. C. Moss, C. J. Hardaway, J. C. Richert and J. Sneddon, Microchem. J., 2010, 95, 5-10.

46 K. V. Kumar, J. Hazard. Mater., 2006, 137, 1538-1544.

47 W. J. Malfait, S. Zhao, R. Verel, S. Iswar, D. Rentsch, R. Fener, Y. Zhang, B. Milow and M. M. Koebel, Chem. Mater., 2015, 27, 6737-6745.

48 N. Leventis, C. Sotiriou-Leventis, G. Zhang and A.-M. M. Rawashdeh, Nano Lett., 2002, 2, 957-960.

49 S. Radi, S. Tighadouini, M. E. Massaoudi, M. Bacquet, S. Degoutin, B. Revel and Y. N. Mabkhot, J. Chem. Eng. Data, 2015, 60, 2915-2925.

50 J. Feng, D. Le, S. T. Nguyen, V. T. C. Nien, D. Jewell and M. D. Hai, Colloids Surf., A, 2016, 506, 298-305.

51 F. Shi, L. Wang and J. Liu, Mater. Lett., 2006, 60, 3718-3722. 52 S. Kabiri, D. N. H. Tran, S. Azari and D. Losic, ACS Appl. Mater. Interfaces, 2015, 7, 11815-11823.

53 M. Kruk and M. Jaroniec, Chem. Mater., 2001, 13, 3169-3183. 54 B. Qiu, J. Guo, X. Zhang, D. Sun, H. Gu, Q. Wang, H. Wang, X. Wang, X. Zhang, B. L. Weeks, Z. Guo and S. Wei, ACS Appl. Mater. Interfaces, 2014, 6, 19816-19824.

55 Z. Li, D. Xiao, Y. Ge and S. Koehler, ACS Appl. Mater. Interfaces, 2015, 7, 15000-15009.

56 Y. Li, M. D. Chen, X. Wan, L. Zhang, X. Wang and H. Xiao, RSC Adv., 2017, 7, 53899-53906.

57 J. P. Vareda and L. Durães, Environ. Technol., 2017, 1-13.

58 X. Luo, H. Yu, Y. Xi, L. Fang, L. Liu and J. Luo, RSC Adv., 2017, 7, 25811-25820.

59 F. S. Awad, K. M. AbouZeid, W. M. A. El-Maaty, A. M. El-Wakil and M. S. El-Shall, ACS Appl. Mater. Interfaces, 2017, 9, 34230-34242. 
60 P. Yu, H. Q. Wang, R. Y. Bao, Z. Liu, W. Yang, B. H. Xie and M. B. Yang, ACS Sustainable Chem. Eng., 2016, 5, 1557-1566.

61 A. S. K. Kumar, S. Kalidhasan, V. Rajesh and N. Rajesh, Ind. Eng. Chem. Res., 2012, 1031, 58-69.

62 K. P. Eliodorio, V. S. Andolfatto, M. R. G. Martins, B. P. D. Sá and E. R. Umeki, Cellulose, 2017, 24, 1-12.

63 Q. Zheng, Z. Cai and S. Gong, J. Mater. Chem. A, 2014, 2, 3110-3118.

64 Z. Hanif, S. Lee, G. H. Qasim, I. Ardiningsih, J.-A. Kim, J. Seon, S. Han, S. Hong and M.-H. Yoon, J. Mater. Chem. A, 2016, 4, 12425-12433.
65 A. M. Donia, A. M. Yousif, A. A. Atia and H. M. Abd El-Latif, J. Dispersion Sci. Technol., 2014, 35, 380-389.

66 H. Ramadan, A. Ghanem and H. El-Rassy, Chem. Eng. J., 2010, 159, 107-115.

67 A. Dutta, Y. Diao, R. Jain, E. R. Rene and S. Dutta, J. Environ. Eng., 2015, 142, C4015014.

68 H. T. Fan, J. X. Liu, H. Yao, Z. G. Zhang, F. Yan and W. X. Li, Ind. Eng. Chem. Res., 2014, 53, 369-378. 